\title{
A TRANSFORMAÇÃO DAS PRÁTICAS PROFISSIONAIS DOCENTES TENDO COMO REFERÊNCIA A METODOLOGIA TELESSALA ${ }^{\mathrm{TM}}$ : UM ESTUDO DE CASO DO PROGRAMA AUTONOMIA.
}

\author{
PROFESSIONAL TEACHING PRACTICES TRANSFORMATION WITH \\ REFERENCE TO TELESSALA METHODOLOGY ${ }^{\mathrm{TM}}$ : A CASE STUDY OF \\ AUTONOMY PROGRAMME.
}

Ana Teresa Pollo Mendonça ${ }^{1}$

Ariana Cosme ${ }^{2}$

\section{RESUMO}

Nesse artigo, analisam-se as transformações nas práticas pedagógicas de educadores que utilizaram a Metodologia Telessala ${ }^{\mathrm{TM}}$ no Programa Autonomia entre 2009 e 2015, uma parceria entre a Fundação Roberto Marinho (FRM) e a Secretaria de Estado de Educação do Rio de Janeiro (SEEDUC), Brasil, que visava a aceleração de estudos para a conclusão da Educação Básica de alunos em distorção idade-série. Procura-se compreender quais as mudanças que ocorreram na sua identidade profissional e pessoal a partir do trabalho unidocente, interdisciplinar e organizado de forma modular e não seriada; com um currículo contextualizado, problematizado e vivenciado através de uma dinâmica em que o professor assume o papel de mediador pedagógico e o conhecimento é construído coletivamente junto aos educandos, divididos em quatro equipes. Para esse trabalho, os docentes passaram por um processo de formação continuada, no início de cada módulo, onde se esperava que fortalecessem pressupostos teórico-metodológicos, como a Leitura de Imagem e a escrita do Memorial e dialogassem com a experiência de outros professores; durante os acompanhamentos pedagógicos em sala de aula que objetivavam identificar as suas conquistas e dar atenção aos desafios; e nos encontros de planejamento em grupo, com a presença da Equipe Multidisciplinar. Reflete-se ainda sobre a possibilidade de aplicação dessa didática alternativa no ensino regular ou em outros contextos educacionais, tendo em vista as suas contribuições para a melhoria do processo de ensino-aprendizagem em contextos de elevados índices de fracasso e evasão escolar.

PALAVRAS-CHAVE: Metodologia Telessala ${ }^{\mathrm{TM}}$; Programa Autonomia; tranformação; práticas docentes; identidade docente.

\begin{abstract}
This article seeks to analyze the transformations in the pedagogical practices of educators who used the Telessala Methodology ${ }^{\mathrm{TM}}$ in the Autonomy Programme between 2009 and 2015, a partnership between Roberto Marinho Foundation (FRM) and Rio de Janeiro State Education Department (SEEDUC), Brazil, which aims accelerate the studies of students with discrepancy between age and grade for the conclusion of Basic Education. It seeks to understand what changes have occurred in their professional and personal identity as single teachers with an interdisciplinary and not-serial but modular organized work; a contextualized and problematized curriculum experienced through a routine in which the teacher assumes the role of pedagogical mediator and the knowledge is constructed collectively with the students, divided in four Teams. For this, they undergo through a process of continuous training, at the

\footnotetext{
${ }^{1}$ Bacharel em Jornalismo, Licencianda em História, Mestre em História Social da Cultura pela PUC-Rio, doutoranda em Ciências da Educação pela Univeridade do Porto, Portugal, professora de pré-vestibulares comunitários, fomração de professores EAD e consultora de projetos, programas e políticas públicas de aceleração de estudos e correção de fluxo para jovens e adultos em distorção idade-série.

${ }_{2}^{2}$ Professora Doutora da Faculdade de Psicologia e de Ciências da Educação da Universidade do Porto, Portugal.
} 
beginning of each module, where they strengthen the theoretical and methodological assumptions, as Image Reading and the Memorial writing and dialogue with other teachers experiences; during the pedagogical accompaniments into the classrooms, that aim to identify their achievements and give attention to the challenges; and in the collective planning meetings with the presence of the multidisciplinary team. Reflect about the possibility of applying this alternative didactic in regular education or other educational contexts, considering their contributions to the quantitative and qualitative improvement of the teaching and learning process in situations of high failure rates and school dropout.

KEY-WORDS: Telessala Methodology ${ }^{\mathrm{TM}}$; Autonomy Programme; transformations; teaching practices; teaching identity.

\section{CONTEXTO DA INVESTIGAÇÃO}

A Metodologia Telessala ${ }^{\mathrm{TM}}$, desenvolvida pela Fundação Roberto Marinho (FRM), utiliza os materiais didáticos (livros e teleaulas) para o Ensino Fundamental e Médio do TELECURSO $^{\mathrm{R}}$ que, desde 1978, possibilita aos jovens e adultos concluírem, à distância, o Ensino Básico, na modalidade "supletivo". Em 2001, o TELECURSOR foi reconhecido como currículo de referência nacional para a avaliação de jovens e adultos através do Exame Nacional para Certificação de Competências de Jovens e Adultos (Encceja).

A partir de 1995, o TELECURSO ${ }^{\mathrm{R}}$ começou a ser aplicado presencialmente, em salas de aula de escolas públicas brasileiras, com o apoio de um professor da rede, em projetos, programas e políticas públicas de aceleração de estudos e correção de fluxo para jovens e adultos em distorção idade-série ou que não concluíram a Educação Básica, em parceria com governos municipais e estaduais - dentre eles o Programa Autonomia, da Secretaria de Estado de Educação do Rio de Janeiro (SEEDUC). Surgiu, então, a Metodologia Telessala ${ }^{\mathrm{TM}}$.

Os projetos, programas e políticas públicas que utilizaram a Metodologia Telessala $^{\mathrm{TM}}$ em Estados do Brasil como o Acre, o Amazonas, o Pará, Rondônia, Distrito Federal, Rio Grande do Norte, Pernambuco, Paraíba, Minas Gerais, Rio de Janeiro, dentre outros, desde 1995, já implantaram mais de 32 mil salas de aula, formaram mais de 7 milhões de estudantes e mais de 40 mil professores - só o Programa Autonomia formou, entre 2009 e 2014, 63 mil estudantes. Daí a sua relevância e ineditismo em ser estudado.

Segundo dados do Instituto Nacional de Estudos e Pesquisas Educacionais Anísio Teixeira (INEP), do Ministério da Educação (MEC), no ano de 2008, o Estado do Rio de Janeiro apresentava uma taxa de distorção idade-série de 36,2\% para o Ensino Fundamental e 49,1\% para o Ensino Médio. Os resultados do Índice de Desenvolvimento da Educação Básica (IDEB) 
indicavam que o Estado do Rio de Janeiro ocupava a 26ª (vigésima sexta) posição no ranking nacional, com elevado índice de reprovação e evasão escolar.

Para tentar reverter essa situação, em 2009, através do Contrato no 38/2008 firmado com a Fundação Roberto Marinho, e da Resolução/SEEDUC n ${ }^{\circ} 4.295 / 2009$, o Programa Autonomia foi implantado. Em 2014, a taxa de distorção idade-série havia caído para 32,7\% no Ensino Fundamental e 31,8\% no Ensino Médio, e o Estado do Rio de Janeiro subido para o 4ํㅜㅇ (quarto) lugar no ranking do IDEB. Cabe destacar aqui o plano de municipalização do Ensino Fundamental no Brasil, e de responsabilização dos Estados com o Ensino Médio.

Desde a década de 1990, a parceria público-privada é um tema polêmico. Embora seja o poder público o responsável por criar e universalizar as políticas educacionais, o Terceiro Setor possa (...) propor, impulsionar e acompanhar políticas públicas, oferecendo respostas ao desafio de melhorar a qualidade da educação oferecida a todos e todas" (GUIMARÃES, 2013, p. 156), e do Programa Autonomia ter sido implementado no contexto de corresponsabilidade expresso no Plano de Desenvolvimento da Educação - PDE (2007-2022), não é nossa pretensão adentrar essa discussão.

Apesar de, em 2009, a Metodologia Telessala ${ }^{\mathrm{TM}}$ ter sido incluída no Guia de Tecnologias Educacionais do MEC, da média de 90\% de aprovação dos estudantes em diferentes estados da federação e da evasão ser mínima, o objetivo desta investigação não é verificar os resultados dos alunos no Programa Autonomia na conclusão da sua escolaridade para isso existem avaliações externas -, mas analisar as transformações nas práticas profissionais docentes de seus professores tendo como referência a Metodologia Telessala ${ }^{\mathrm{TM}}$.

\section{O TEMA CENTRAL E OS EIXOS TEMÁTICOS}

A Metodologia Telessala ${ }^{\mathrm{TM}}$ tem como Tema Central "Uma educação para o desenvolvimento do ser" - um ser sistêmico, holístico, que desenvolva conteúdos não só científicos, mas atitudinais -, trabalhado ao longo de quatro módulos, com duração de um semestre cada, possibilitando aos alunos concluírem a sua escolaridade ao final de dois anos. Cada módulo dessa organização não-seriada corresponde a um grupo de duas (Ensino Fundamental) a quatro disciplinas (Ensino Médio) trabalhadas integralmente e de forma integrada.

A cada módulo corresponde também um eixo temático orientador problematizador, que garante a sua identidade através da reflexão sobre “(...) quatro questões fundamentais à construção da compreensão, da interpretação e da explicação da realidade 
natural e cultural” (GUIMARÃES, 2013: 107): “Quem sou eu?” (O ser humano e sua expressão), eixo temático do módulo I; “Onde estou?” (O ser humano interagindo com o espaço), II; "Para onde vou?” (O ser humano em ação), III; e “Qual a minha missão no mundo?” (O ser Humano e sua participação social) e IV.

\section{A INTERDISCIPLINARIDADE}

A promoção da interdisciplinaridade se baseia no conceito de Complexidade de Morin (2000), que propõe uma reaprendizagem do pensar, por meio da religação de tudo aquilo que nossa educação nos ensinou a separar (p. 41). Morin (2000) questiona que o recorte das disciplinas impossibilita apreender "o que está tecido junto", ou seja, o complexus (p. 41), e que esses saberes compartimentados são inadequados para reconhecer e compreender os problemas de uma realidade inter e transdisciplinar (p. 36).

Para Morin (2015), interdisciplinaridade "pode significar também troca e cooperação, o que faz com que a interdisciplinaridade possa vir a ser alguma coisa orgânica" (p. 115). Na Metodologia Telessala ${ }^{\mathrm{TM}}$, percebe-se essa cooperação entre as disciplinas, rompendo-se as fronteiras entre elas, através de uma rede de conexões - e não de uma grade curricular, que supera a concepção linear de currículo como uma "prisão" -, cujos Parâmetros Curriculares Nacionais (MEC, 1997) foram a base para a construção de uma organização mais flexível.

\section{O PAPEL DO PROFESSOR COMO MEDIADOR PEDAGÓGICO}

Morin (2015) discute que, apesar de os conhecimentos terem atingido um alto grau de sofisticação, a fragmentação de saberes criou especialistas fracos na capacidade de promover a interconexão entre as diversas disciplinas. Não é o seu desaparecimento que se propõe, mas investir em reformas curriculares que possibilitem frear a expansão da autoridade dos experts, "que condena os cidadãos à aceitação ignorante das decisões daqueles que se presumem sabedores, mas cuja inteligência é míope”, e antidemocrática (p. 103).

Crema (1993) reconhece a importância da especialização e ressalta que transcender as disciplinas não significa negá-las, o que se postula é a abertura do professor a uma reflexão mais sistêmica, o que envolveria a dialogicidade entre as disciplinas e os docentes das diferentes áreas do conhecimento, visando a sua complementaridade. "A proposta é transmutar o especialista fechado em especialista pontifex, construtor de pontes (...), que seja capaz, também, além de fracionar, de vincular e restaurar" (p. 140). 
O educador, na Metodologia Telessala ${ }^{\mathrm{TM}}$, apresenta-se, então, como um mediador pedagógico, visão que vai ao encontro do pensamento de autores que defendem a validade de existirem professores polivalentes em todas as áreas da Educação Básica, o que não implica o enfraquecimento da sua formação no conteúdo das disciplinas curriculares. O Programa Autonomia vem possibilitar esse exercício de um paradigma inovador, em que o professor da Telessala, ao contrário do que é esperado no ensino regular, não é um especialista na sua área disciplinar, mas polivalente.

\section{A CONCEPÇÃO DE EDUCAÇÃO COMO PRÁTICA DA LIBERDADE, AUTONOMIA E CIDADANIA}

Freire (1996) afirmava, ao contrário do Paradigma da Instrução (TRINDADE, 2009) - onde o aluno ocupa o lugar do morto, de sujeito transformado em objeto, e a aprendizagem é entendida como a apreensão e não apropriação, de um saber-objeto transmitido pelo professor -, que "ensinar não é transferir conhecimento, mas criar possibilidades para a sua produção ou a sua construção" (FREIRE, 1996, p. 12). Isso porque o aluno "enchido" com conteúdos que contradizem a sua própria forma de estar no mundo, não desenvolve uma postura crítica, conscientizadora (FREIRE, 1996).

Freire (1987), criticava o que denominava de "educação bancária", e denunciava a visão do educando como uma conta "em branco" ou um depositário, e do educador como um depositante, que deposita no educando todo o seu saber, que vai sendo acumulado (p. 33), como que numa "caixa registradora". Para Freire e para a Metodologia Telessala ${ }^{\mathrm{TM}}$, o aluno não é uma tabula rasa e é previsto que ele já traga um conhecimento prévio oriundo de sua prática cotidiana, do seu dia-a-dia.

A concepção bancária da educação traz em si uma contradição educador-educando que precisa ser superada: ela "nega a dialogicidade como essência da educação e se faz antidialógica" (FREIRE, 1987, p. 39). Freire (1996) rejeitava essa dicotomia professor-aluno, que separa as responsabilidades na construção do conhecimento, propondo em seu lugar uma partilha colaborativa desses saberes, pois “(...) quem ensina aprende ao ensinar e quem aprende ensina ao aprender" (FREIRE, p. 1996, p. 12).

Freire (1967) insistia na superação da descrença no educando, na sua incapacidade de discutir seus próprios problemas, porque acreditava que "ninguém ignora tudo. Ninguém tudo sabe”. (p. 104-105). Meirieu (2005) traz o "postulado da educabilidade", segundo o qual "ninguém pode ensinar sem postular que o outro, diante dele, é educável” (MEIRIEU, p. 74). 
Mas para isso é preciso que se realize "um grande esforço para imaginar novos métodos" (p. 75) para combater o fatalismo e a exclusão escolar de alunos do círculo dos "eleitos".

\section{A ORGANIZAÇÃO DO ESPAÇO NA TELESSALA}

O conceito de escola é um conceito carregado de passividade e acomodação, onde o "bom educando não 'entra' questionando, perguntando na aula do educador. Sua entrada é pela quietude de ouvinte" (FREIRE, 2010, p. 149). "Como aprender a discutir e a debater com uma educação que impõe? Ditamos ideias. Não trocamos ideias. Discursamos aulas" (FREIRE, 1967, p. 97). Por isso, quando Freire lançou os Círculos de Cultura, no lugar do professor propôs o coordenador de debates, reduzindo ao mínimo a sua intervenção direta, expositiva.

Cosme (2009) analisa o dilema de Perrenoud (2001), “em torno da palavra e do silêncio", que confronta a impossibilidade do professor "ter o privilégio de impor o silêncio e de rompê-lo" (PERRENOUD, 2001, p. 65) e, "simultaneamente, esperar que os alunos participem ativamente no quotidiano da sala de aula" (COSME, 2009, p. 67). Para isso, a Metodologia Telessala ${ }^{\mathrm{TM}}$ propõe a arrumação do espaço em círculo, com as carteiras dispostas de modo a "falar" da flexibilidade indispensável ao processo de ensino-aprendizagem (GUIMARÃES, 2013).

O círculo é o símbolo universal de integração e unidade. Atribuir sentido pedagógico à organização física da sala significa prover espaços livres para atividades que possibilitem olharem uns aos outros de frente e se comunicarem de igual para igual, e estimulem uma construção de aprendizagem coletiva e a autonomia dos estudantes. "Assim como uma prática cooperativa, educadores e educandos concretizam aquilo que Paulo Freire ensinou: ninguém educa ninguém; ninguém se educa sozinho, aprendemos todos em comunhão". (GUIMARÃES, 2013, p. 9).

\section{OS TRÊS PILARES DA METODOLOGIA TELESSALA ${ }^{\mathrm{TM}}$ : AS EQUIPES, A LEITURA DE IMAGEM E O MEMORIAL}

Delors (1999) sugere que a prática pedagógica deve se preocupar em desenvolver quatro aprendizagens fundamentais: aprender a conhecer, aprender a fazer, aprender a conviver e aprender a ser. São quatro o Pilares da Educação do Relatório para a UNESCO da Comissão Internacional sobre Educação para o Século XXI, e três os fundamentos da Metodologia Telessala ${ }^{\mathrm{TM}}$ : a divisão dos alunos em quatro Equipes Para o Desenvolvimento do Ser, a Leitura de Imagem e a escrita do Memorial do aluno, da Telessala e do professor. 
A divisão dos alunos em quatro equipes: Socialização, Coordenação, Síntese e Avaliação, com responsabilidades bem definidas "contribui para a construção do senso de coletividade, e faz com que os estudantes consigam se constituir em comunidade de aprendizagem" (GUIMARÃES, 2013, p. 60). As equipes para o desenvolvimento do ser ajudam também a desenvolver uma série de competências a habilidades atitudinais e a formar esse ser menos individualista e mais solidário, menos competitivo e mais justo, íntegro.

A equipe de socialização integra a classe e media conflitos, cuidando da autoestima e do bem-estar social; a coordenação é o braço direito do professor na organização do ambiente e faz a ponte entre a Telessala e a gestão escolar; a síntese sistematiza as aprendizagens desenvolvidas e registra a memória afetiva da turma; e a avaliação conduz uma reflexão crítica dos alunos e do professor sobre o processo de ensino-aprendizagem. Ao longo dos módulos, os alunos atuam nas equipes de maneira rotativa. A apresentação pode variar a periodicidade, mas sua postura deve ser diária.

A leitura de imagem é um exercício de leitura de mundo, na mesma lógica que as xilogravuras do artista plástico pernambucano Francisco Brennand eram utilizadas nos Círculos de Cultura de Paulo Freire, como provocadoras de um processo de decodificação da realidade, desejando transformá-lo. "A leitura da palavra não é apenas precedida pela leitura do mundo, mas por uma certa forma de 'escrevê-lo' ou de 'reescrevê-lo', quer dizer, de transformá-lo através de nossa prática consciente" (FREIRE, 2009, p. 20).

A escola moderna costuma valorizar mais a leitura de um texto escrito, a grafia de uma língua, do que suas linguagens. Na Metodologia Telessala ${ }^{\mathrm{TM}}$, é dada uma importância fundamental aos textos imagéticos, sejam eles estáticos ou em movimento, como a Teleaula, que são vistos como um conjunto infinito de possibilidades pedagógicas e não como meras ilustrações. Fundamentais para "conferir concretude aos conceitos mais abstratos, auxiliando o processo de construção dos conhecimentos" (GUIMARÃES, 2013, p. 70).

O memorial, mais do que um caderno de escrita, é um instrumento de reflexão sobre a prática docente e um registro das aprendizagens construídas individual e coletivamente pelos estudantes. Ele não é uma agenda do dia, é um diário de bordo onde professor e aluno relatam suas experiências pedagógicas e pessoais, e se descobrem como atores e autores de sua própria história. O memorial embasa “(...) o processo avaliativo na Metodologia Telessala, expressando o crescimento das pessoas neles engajadas e possibilitando a tomada de decisões" (GUIMARÃES, 2013, P. 148). 
O memorial tem impacto sobre a formação continuada do professor da Telessala porque propicia a autoavaliação processual da sua trajetória e o obriga a se posicionar em um paradigma - e a se questionar o que ensina, como ensina, por que ensina, "a favor de quem e do quê, portanto contra quem e contra o quê, fazemos a educação" (FREIRE, 2009, p. 23). Segundo Freire., na concepção de educação democrática, o educador é “também é escritor que registra o seu fazer pedagógico, questionando-se, sobre as hipóteses de seu pensar" (FREIRE, 2010, p. 56).

\section{O CONCEITO DE AVALIAÇÃO TRANSFORMADORA: DIAGNÓSTICA, PROCESSUAL E FORMATIVA}

A avaliação na Metodologia Telessala ${ }^{\mathrm{TM}}$ é realizada de maneira diferenciada do ensino regular, pois seu objetivo não é aferir a quantidade de conteúdos apreendidos, mas desenvolver habilidades e competências. “Ao contrário da avaliação tradicional, que enfatiza o negativo, a avaliação na Metodologia Telessala focaliza e celebra o positivo, o crescimento das competências dos envolvidos” (GUIMARÃES, 2013, p. 148). Erros são considerados válidos para um ajuste dos instrumentos de avaliação, diversificados e precisos, e criteriosamente estabelecidos previamente entre professor e alunos. Por isso, ela é diagnóstica.

Para Firme (1980), é impossível concordar com a ideia de que reprovar estudantes contribui para que aprendam mais. A avaliação, como acontece na sala de aula, é coragem, e não medo; é promocional, e não classificatória, é criteriosa, e não arbitrária; é participativa, e não autoritária; é transparente, e não secreta; é negociação, e não imposição. O grande desafio é desconstruir uma concepção de avaliação vigilante e punitiva, e que esta seja ética, respeite o direito de aprender, tanto do aluno quanto do professor. Se for assim conduzida, trará benefícios tanto para os avaliados como para os avaliadores.

A avaliação na metodologia Telessala ${ }^{T M}$ é processual porque ocorre durante todo o processo de ensino-aprendizagem, e não apenas de forma pontual, através de testes padronizados que avaliam um conteúdo apreendido de forma descontextualizada, desproblematizada, pouco significativa e que faz pouco sentido. Uma das maiores dificuldade desse modelo de avaliação está na forma de "quantificar" esse conhecimento que não é dado, mas construído a partir da relação entre esses conteúdos e os conhecimentos prévios dos alunos, e um processo centrado em valores subjetivos como o desenvolvimento da criatividade, da criticidade e da leitura de mundo. 
E é formativa porque nela se avalia as perspectivas de futuro, a ampliação dos horizontes de expectativas, as novas possibilidades. Para isso, urge capacitar o professor para avaliar o aluno em todas as suas potencialidades, utilizando o melhor de sua sensibilidade e de sua competência para captar indicadores de avanço e sinais de preocupação; é capacitá-lo para se autoavaliar como educador e avaliar a escola e todo o contexto educacional; é capacitá-lo para entender criticamente que a responsabilidade não é de uma só instância, mas de todos envolvidos e interessados na educação, com o mais elevado propósito de se promover o aperfeiçoamento.

\section{AS ETAPAS DO TRABALHO PEDAGÓGICO DA TELESSALA}

Na prática, a metodologia Telessala ${ }^{\mathrm{TM}}$ funciona de acordo com a seguinte dinâmica: a) atividade integradora, que pode ser realizada pela equipe de socialização; b) problematização, que permite ao professor diagnosticar o conhecimento prévio do aluno sobre o conteúdo a ser enfatizado, despertando a curiosidade para a pesquisa e motivação para a Teleaula.

Em uma Telessala, esse conteúdo é oferecido de forma contextualizada e problematizada a partir de uma "situação problema" presente no contexto sócio, econômico e político dos estudantes, pois só é possível se apropriar de um objeto de conhecimento, dar-lhe significado, se a comunicação entre o saber - o patrimônio cultural que é dever da escola valorizar e direito dos alunos se apropriarem -, os estudantes e o professor for clara (TRINDADE, 2009).

Behrens (2013) sugere que, nessa primeira fase, o professor proponha a contextualização, a localização histórica da produção daquele conhecimento, e a problematização do tema a ser abordado, pois o aluno precisa refletir por que, para que ele vai trabalhar com aqueles conteúdos, e a quem eles servem. O papel do professor é o de um provocador que instiga os alunos, nesse processo de ensino-aprendizagem, a questionar o que vão apreender da escola (BEHRENS, 2013, p. 99).

Com duração média de 15 minutos, as Teleaulas também cumprem essa função de problematizar e apresentar os conteúdos que serão trabalhados, utilizando diversas linguagens televisivas como a locução, a reportagem e a entrevista com o público leigo e especialistas; além da dramaturgia teatral, televisiva e cinematográfica; da música; das artes plásticas; de jornais e documentos oficiais e de época; e do uso de ilustrações, fotografias e mapas cartográficos. 
A leitura de imagem propicia também uma alfabetização do olhar, um resgate do texto visual que os alunos viram (personagens, cenários, legendas), ouviram (falas, diálogos e músicas) e sentiram (os sentimentos das personagens e os próprios sentimentos que foram despertados); informações que depois são contextualizadas em um tempo cronológico e histórico, localizadas em um espaço; e transformadas em conhecimento através da sua conceitualização, reflexão sobre e avaliação.

Após a tríade problematização/Teleaula/leitura de imagem, é que se iniciam as atividades com o livro-texto, individuais ou em grupos - grupos esses que realizarão também as atividades complementares, e socializarão essas atividades. Suas produções, que devem utilizar diversas linguagens, deverão ser expostas nas paredes das salas como instrumentos de consulta. O dia finaliza com a avaliação do dia, que pode ser realizada pelas equipes de síntese e de avaliação.

\section{AS FORMAÇÕES CONTINUADAS E OS ACOMPANHAMENTOS PEDAGÓGICOS}

Para trabalhar com a Metodologia Telessala ${ }^{T M}$, os professores passam por uma formação continuada, presencial, no início de cada módulo - de 8hs diárias, 40hs horas semanais -, onde vivenciam os pressupostos seus teóricos-metodológicos na prática - pois precisam desenvolver as mesmas competências e habilidades que os estudantes na Telessala. Nas capacitações, os formadores não dão palestras, mas mediam dinâmicas e debates entre os professores acerca de sua experiência no Programa Autonomia, discutindo sobre o ensino regular e refletindo sobre suas transformações.

Os acompanhamentos pedagógicos, que são realizados por meio de visitas às salas de aula pelos consultores da FRM - a cada módulo, por amostragem -, e pelos supervisores da SEEDUC - semanalmente ou quinzenalmente - também fazem parte da formação continuada. Neles, consultores e supervisores dialogam com gestores, professores e alunos, identificando suas conquistas e dando atenção a seus desafios, e deixam claro que seu papel e postura ali são de parceria na construção desse modelo pedagógico e não de fiscais.

Além disso, professores e supervisores têm encontros semanais ou quinzenais de planejamento coletivo com a equipe multidisciplinar - composta por professores da rede especialistas nas disciplinas do módulo -, para estudar os conteúdos das disciplinas do módulo e planejar suas aulas. São muitos também os materiais à disposição dos professores: o livro do professor, o caderno de metodologia, os cadernos de textos, de formação das disciplinas, a matriz de referência para a avaliação do Telecurso ${ }^{\mathrm{R}}$, as sinopses das Teleaulas, entre outros. 


\section{PARADIGMA E METODOLOGIA DE INVESTIGAÇÃO}

O objetivo geral desse artigo, que se pretende um recorte da tese realizada no Programa Doutoral em Ciências da Educação da Universidade do Porto, Portugal, é analisar as transformações das práticas pedagógicas docentes de professores que trabalharam no Programa Autonomia entre 2009 e 2015. Também são objetivos específicos interpretar se houve uma afirmação ou compreender as mudanças que ocorreram na sua identidade profissional e pessoal, além de refletir sobre as possibilidades de aplicação da Metodologia Telessala $^{\mathrm{TM}}$ em outros contextos educacionais.

Essa investigação se insere dentro do paradigma fenomenológico-interpretativo ou sócio-crítico dos neomarxistas da Escola de Frankfurt, comprometidos com as mudanças sociais, a partir do retorno as ideias de Karl Marx em sua obra Teses sobre Feuerbach, segundo o qual "até agora, os filósofos limitaram-se a interpretar o mundo de maneiras diferentes; o que importa, porém, é transformá-lo" (AMADO, 2013, p. 52). Afinal, é voltada para a análise das práticas pedagógicas de professores, assumindo-se o caráter reflexivo e político do campo das Ciências da Educação.

A pesquisa se baseia numa abordagem metodológica qualitativa, mais adequada para compreender e interpretar uma realidade singular e complexa, sem nunca ter sido nosso objetivo eleger a Metodologia Telessala ${ }^{\mathrm{TM}}$ como um modelo "ideal”. Stake (2012), sobre as diferenças entre uma investigação qualitativa e uma quantitativa, afirma que elas estão no objetivo de se analisar - de forma mais aprofundada -, e não explicar - de forma generalizada, como se houvessem causas e consequências lógicas que pudessem dar margem a estatísticas -, o objeto de investigação.

Optamos pelo estudo de caso pois trata-se de aprofundar um tema específico e, portanto, é preciso descrevê-lo, conceitualizá-lo, teorizá-lo e contextualizá-lo em detalhes para poder analisar, compreender e interpretar essa transformação em profundidade. Morgado (2012) aponta quatro características de um estudo de caso: é um estudo holístico, que leva em conta a complexidade do contexto; empírico, sujeito a recolha de dados através de instrumentos ou técnicas; interpretativo, não se pretende imparcial; e empático, que leva em consideração as vozes dos atores envolvidos.

Como procedimento de análise foi utilizada a técnica de análise de conteúdo, com o propósito de dar voz aos "ditos", "não ditos" e aos "silêncios" dos investigados, conferindolhes o estatuto de coautores do texto, o que exige do investigador competências como saber 
ouvir e ser fiel na transcrição das falas e manter a confidencialidade dos participantes. Segundo Bardin (1995), essa “técnica de ruptura” é "útil para o especialista das ciências humanas, quanto mais ele tenha sempre uma impressão de familiaridade face ao seu objeto de análise” (1995, p. 28).

O trabalho empírico foi desenvolvido, então, a partir da análise de conteúdo de entrevistas individuais semiestruturadas com professores estaduais de diferentes regiões do Estado do Rio de Janeiro, cuja riqueza da estratégia foi permitir que viessem à tona experiências únicas desses professores, pois o objetivo não era obter simples respostas de $\operatorname{sim}$ ou não, do quê e quanto, mas como e porquê. Assim, foram selecionadas questões estruturantes, que foram adaptadas para perguntas de um guião orientador e posteriormente agrupadas em subcategorias de análise. Elegemos aqui algumas delas:

Q. 1.: Os desafios e conquistas que os professores enfrentaram e desenvolveram ao trabalhar com a Metodologia Telessala ${ }^{\mathrm{TM}}$ no Programa Autonomia; Q. 2.: Os preconceitos que sofreram por parte dos diretores das escolas e de professores do ensino regular; Q. 3.: Os desafios e conquistas que os professores enfrentaram e desenvolveram ao trabalhar com a unidocência e o conteúdo interdisciplinar; Q. 4.: Com o Tema Central e os eixos temáticos trabalhados de forma modular e não seriada; Q. 5.: Com as etapas do trabalho pedagógico diário da Telessala;

Q. 6.: As formações de professores e os acompanhamentos pedagógicos vistos como um processo de formação continuada; Q. 7.: Enquanto momentos de reflexão sobre a prática docente; Q. 8.: As transformações na prática pedagógica docente; Q. 9.: A afirmação ou as mudanças na identidade profissional e pessoal; Q. 10.: As mudanças na relação e no olhar professor-aluno; Q. 11.: A possibilidade de aplicação dessa didática alternativa no ensino regular ou em outros contextos educativos; Q. 12.: As novas possibilidades de escola.

\section{ALGUNS RESULTADOS}

Com relação aos desafios que enfrentaram ao utilizar a Metodologia Telessala ${ }^{\mathrm{TM}}$ no Programa Autonomia, os professores relataram que ela não é uma receita pronta, em que basta misturar os ingredientes e seguir as instruções para dar certo; ao longo do processo eles enfrentaram tabus e quebraram paradigmas para se adaptar e conseguir adaptá-la às suas realidades de sala de aula. Os educadores também expuseram que tiveram que se reformular, após décadas de carreira docente, para trabalhar com dinâmicas que não as do ensino 
tradicional, e que as etapas pedagógicas diárias da Telessala necessitavam ser cuidadosamente planejadas, assim como os conteúdos interdisciplinares profundamente estudados.

Por ser mais um projeto, dentre outros que já foram implantados pela SEEDUC, além de ser uma parceria público-privada com a FRM, o Programa Autonomia sofreu preconceito por parte de diretores e professores do ensino regular. Algumas Telessalas se localizavam em áreas isoladas da escola e alunos do projeto chegaram a ter o horário de entrada e do recreio modificados para que não convivessem com os alunos do ensino regular. Alguns docentes tiveram dificuldade em fazer amizade na sala dos professores, onde eram ignorados ou ouviam comentários velados a respeito da Metodologia Telessala ${ }^{\mathrm{TM}}$, voltada para esse perfil de jovens e adultos rotulados e estigmatizados como o "lixo da escola".

A respeito das conquistas desenvolvidas, os professores comentaram que, por estarem há muitos anos trabalhando com a metodologia do ensino regular, acabaram por se acomodar, e que utilizar a Metodologia Telessala ${ }^{\mathrm{TM}}$ no Programa Autonomia fez com que saíssem da sua "zona de conforto". Alguns docentes, já próximos da aposentadoria, que já haviam passado pela coordenação pedagógica e pela direção da escola, mencionaram que recuperaram o ideal do magistério presente no início da carreira ao voltar para a sala de aula, e que os que pensavam em desistir da profissão, desenvolveram novas estratégias de ensinoaprendizagem que facilitaram o seu trabalho, mesmo com o aumento das suas responsabilidades e a ampliação do seu papel.

Quanto ao trabalho com o tema central e os eixos temáticos de forma modular e não seriada, passaram a valorizar os conteúdos atitudinais que o currículo científico não prioriza, a se preocupar em resgatar a autoestima daquele aluno a quem a vida sempre disse não, a acreditar que ele é capaz de voltar a estudar e aprender, e que, mesmo o aluno em distorção idade-série, tem sonhos. Em pouco tempo, esses alunos amadureceram e se tornaram co-responsáveis pelo seu aprendizado, descobrindo-se como sujeitos de direito e se situando como cidadãos no mundo. Hoje é impossível para esses professores expor o conteúdo de uma disciplina sem antes contextualizá-lo e problematizá-lo, fazer uma relação desses com a vida.

Sobre o trabalho interdisciplinar com a unidocência, os docentes lembraram que durante a graduação o professor assimila a importância da especialização e acaba se tornando um "detentor" e defensor de um conhecimento científico fragmentado, sem ligação com as demais disciplinas, sobretudo com as quais não se identificam. Ressaltaram que com o trabalho unidocente, o especialista torna-se mais completo, até na sua própria área de formação. Esses educadores também destacaram que, ao exercer o papel de mediadores que, assim como os 
alunos, também estavam ali para aprender, desenvolveram uma nova relação professor-aluno, não mais autoritária, mas democrática, inclusive na organização da Telessala, em círculo.

No tocante as etapas do trabalho pedagógico diário da Telessala, os docentes reconheceram que a divisão dos alunos em equipes contribuiu para que eles se identificassem enquanto comunidades de aprendizagem e percebessem que aprendem não só com o professor, mas com a ajuda dos seus pares. A leitura de imagem também foi importantíssima para educar o olhar desse aluno na observação da realidade fora da sala de aula, e a desenvolver a sua criticidade, no que passaram a se mobilizar e a serem mais atuantes na comunidade escolar. $\mathrm{O}$ memorial também foi citado como um instrumento que aproximou muito os alunos do professor, pois ajudou a desenvolver a confiança entre eles e a criar assim uma relação verdadeiramente de afeto.

Acerca das formações de professores, os docentes foram enfáticos ao afirmar que sem uma formação continuada não é possível se trabalhar ao longo de dois anos numa Telessala com esse perfil de jovens e adultos que vem sendo reprovado no Ensino Fundamental e Médio ou que evadiu da escola há anos. Por isso a importância, não só da fundamentação teóricometodológica e da vivência da Metodologia Telessala ${ }^{\mathrm{TM}}$, mas fundamentalmente da troca entre esses professores nas formações presenciais e do apoio recebido por parte dos consultores da FRM e dos supervisores da SEEDUC - que não exerciam uma postura de fiscais - durante os acompanhamentos pedagógicos nas escolas.

No que concerne às formações enquanto momentos de reflexão sobre a prática docente, professores lamentaram que eles tenham entrado e saído das Universidades sem que tenha lhes sido proposto trabalhar com práticas pedagógicas inovadoras, mas que ao longo desse processo amadureceram muito profissionalmente. Professores veteranos admitiram que antes de trabalhar no Programa Autonomia desconheciam outras metodologias de ensinoaprendizagem, e costumavam se eximir de responsabilidade e colocar a culpa unicamente no "sistema", minando a esperança de professores novatos que chegavam à escola com a cabeça aberta, cheia de novas ideias. As formações propiciaram, então, uma autocrítica e avaliação.

Esses educadores observaram que só perceberam o quanto suas práticas pedagógicas docentes estavam modificadas quando voltaram a lecionar no ensino regular. Assumiram que eram conteudistas, que pensavam que o melhor a fazer pelo aluno era dar todo o conteúdo para que ele passasse de ano, mas que não é aplicando uma avaliação pontual e a quantificando em uma nota que eles vão conseguir concluir o Ensino Fundamental e Médio com qualidade. Hoje, conseguem enxergar além dos números e não tem mais um alto índice de 
reprovação e evasão, pois aprenderam a observar e respeitar o tempo de cada um para desenvolverem as habilidades e competências necessárias para o exercício da cidadania e autonomia.

Dando importância às afirmações ou mudanças na identidade pessoal e profissional, para esses educadores sua atividade pode ser claramente marcada pelo antes e o depois da vivência do Autonomia porque, segundo eles, ninguém passa pelo programa ileso. Esses professores têm a Metodologia Telessala ${ }^{\mathrm{TM}}$ como um divisor de águas em suas vidas, eram uns quando entraram e são outros depois que saíram. Agradecem os anos que trabalharam e se pudessem, teriam continuado no programa, pois se realizaram profissionalmente. Sentem-se órfãos, já que desenvolveram uma sensação de pertencimento ao que apelidaram de "família Autonomia". Dizem-se pessoas que acreditam na Metodologia Telessala ${ }^{\mathrm{TM}}$.

No que se refere à mudança na relação e no olhar professor-aluno, suas posturas mudaram porque se transformaram como seres humanos, não só na escola pública como também na particular. A Metodologia Telessala ${ }^{\mathrm{TM}}$ os fez refletir sobre o quê, por quê, para quê, para quem e contra quem educar, a ter esse olhar mais cidadão. Hoje, como profissionais, têm a certeza de que estão fazendo algo pelos alunos, diferentemente de antes, quando estavam ali apenas cumprindo o papel de passar o conteúdo. Passaram a se identificar não mais como professores, mas como educadores, preocupados em se despir de preconceitos para trabalhar questões sociais como a violência escolar e o tráfico de drogas.

Tendo em consideração as possibilidades de aplicação dessa didática alternativa em outros contextos profissionais, esses professores realçaram que seria fundamental não só para corrigir a distorção idade-série, mas para trabalhar com a desmotivação e a falta de concentração de alunos e professores do próprio ensino regular. Entretanto, velhos professores, mesmo cansados das velhas práticas, sentem-se inseguros em deixar de lado os amarelados planos de aula. São muitos os saudosistas - “ah, mas no meu tempo não era assim” -, que se recusam a se reciclar, a se qualificar continuamente, pois não aceitam que os tempos mudaram, que os alunos são outros, e chegam nas capacitações do Estado dizendo que não ganham para isso.

Esses educadores acreditam que a Metodologia Telessala ${ }^{\mathrm{TM}}$ possa ser uma alternativa à crise da escola pública. É a instituição escolar que está desinteressante. Os alunos gostam da escola, mas não gostam das salas de aula, não sentem prazer em aprender em uma sala de aula organizada em fileiras. É preciso que se aposte em metodologias que coloquem os estudantes no centro da aprendizagem, que enxerguem esse aluno como um indivíduo que tem 
conhecimento e que deem voz a ele. Que o professor abandone sua posição de dono do saber e se torne um parceiro de troca na construção coletiva da aprendizagem. É preciso um currículo que leve em consideração às diversidades e às diferenças entre eles, sendo contextualizado e problematizado.

\section{CONSIDERAÇÕES FINAIS}

No que tange ao objetivo geral deste artigo, dos resultados da análise de conteúdo das entrevistas individuais semiestruturadas podemos admitir que houve uma transformação na prática pedagógica docente desses professores que utilizaram a Metodologia Telessala ${ }^{\mathrm{TM}}$ no Programa Autonomia entre 2009 e 2015.

A partir do tema central - Uma educação para o desenvolvimento do ser - e dos eixos temáticos - “Quem sou eu?” (O ser humano e sua expressão), “Onde estou?” (O ser humano interagindo com o espaço), "Para onde vou?” (O ser humano em ação), e “Qual a minha missão no mundo?” (O ser Humano e sua participação social) - passaram a valorizar não só os conteúdos científicos, mas também os atitudinais, éticos, importante para o desenvolvimento da autoestima, da responsabilidade, do senso de coletividade e da autonomia dos alunos enquanto cidadãos, e a questionar o currículo oficial que é considerado patrimônio cultural da escola, desconstruindo suas reais intenções de produção e a quem ele serve, politizando esse aluno.

O trabalho modular e não seriado, interdisciplinar, permitiu superar essa concepção linear de currículo e possibilitou aos professores unir saberes fragmentados pela necessidade da especialização do profissional na sua formação acadêmica, dividida em licenciaturas sem nexo entre si, e a descobrir que na vida esses saberes não são utilizados de forma desconexa para resolver os problemas, mas integrados. Esses educadores aprofundaram seus estudos, completaram seus conhecimentos e se sentiram mais seguros para atuar inclusive na sua própria área de formação, que foi enriquecida pelos conhecimentos das outras disciplinas, além de terem perdido o medo dessas disciplinas de outras áreas do conhecimento, como as de Exatas.

A convivência diária, ao longo de dois anos de projeto, aumentou a confiança e o respeito dos alunos pelo professor, pois esse passou a conhecer as suas histórias de vida e a se envolver com a sua realidade, ajudando-os a resolver seus problemas pessoais que interferiam no processo de ensino-aprendizagem na escola, chegando a diminuir a violência em sala de aula. A organização da Telessala em círculo, onde todos se veem e se ouvem, e ocupam os mesmos lugares dentro dessa hierarquia escolar, também contribuiu para que se construísse essa 
relação professor-aluno mais horizontal e menos vertical e, consequentemente, mais democrática.

A unidocência foi a grande responsável pela transformação da prática profissional docente desses educadores, pois os obrigou a descer do pedestal e a reconhecer que não são os donos do conhecimento, que não sabe tudo nem sobre a sua própria área de formação, mas que o aluno também traz conhecimentos para a sala de aula, oriundos da sua experiência vida, que muitas vezes põem em cheque sua própria visão de mundo, distante da realidade desses alunos. Ela possibilitou o exercício de humildade necessário para essa mudança de postura e alternância de papel, onde esse conhecimento passa a ser construído coletivamente, não mais transferido de forma expositiva, e onde ele passa também a ser aprendiz.

A contextualização e a problematização dos conteúdos - para que façam sentido de acordo com as suas referências, e tenham significado para a sua vida -, fez com que os alunos se sentissem pertencentes e tivessem prazer em vir para a escola. Também fez com que os professores, ao se abrirem para conhecer a realidade dos alunos, questionassem seus privilégios e desconstruíssem seus preconceitos. Ao provocar a leitura de mundo que precede a leitura da palavra, seus olhares se tornam mais críticos e suas posturas mais politizadas, professores e alunos se enxergam como protagonistas ativos no processo de ensino-aprendizagem, tomando consciência de que são eles os responsáveis pelas transformações que querem ver no mundo.

Através da divisão das equipes - socialização, coordenação, síntese e avaliação -, que desenvolvem fundamentalmente esse aprender a fazer e aprender a conviver, os alunos colaboraram na organização da Telessala, tornando o trabalho do professor menos árduo. A utilização de textos imagéticos como a Teleaula e a leitura de imagem e a diversificação das linguagens facilitadoras da aprendizagem para além da oral e escrita, como a artística, corroborou para animar a criatividade docente e inserir os sentidos também dentro desse processo de ensino-aprendizado. O memorial também serviu como um instrumento de empoderamento tanto do aluno quanto do professor, que ali refletiu sobre e autoavaliou a sua prática e identidade docente.

No que corresponde ao objetivo específico de interpretar se houve uma afirmação ou compreender as mudanças que ocorreram na sua identidade profissional e pessoal, professores que estavam acomodados às metodologias do ensino regular, ao trabalharem com a Metodologia Telessala ${ }^{\mathrm{TM}}$ no Programa Autonomia, por ela não acontecer como que em um passe de mágica, ao vivenciarem as formações continuadas e voltarem a estudar para planejar suas aulas, saíram da sua zona de conforto, enfrentaram tabus como o da unidocência e 
quebraram paradigmas como o da mediação do conhecimento. Refletiram sobre o que é a educação, amadureceram profissionalmente, e ampliaram o seu papel de professor para o de educador.

A passagem de uma escola voltada para a formação de uma elite para uma escola democrática implicou um aumento do quantitativo de alunos e o aparecimento de problemas qualitativos, como o aumento das responsabilidades sociais, a baixa valorização salarial e a consequente desvalorização da profissão na educação pública, que se traduziram na desmotivação pessoal e nos elevados índices de absentismo e abandono profissional. Todavia, professores que sofriam do que pode ser denominado por "mal-estar docente" e já pensavam em desistir da escola, e professores que já estavam perto de se aposentar, resgataram o ideal presente no início da carreira docente, ao se realizar profissionalmente, e se pudessem teriam continuado no projeto.

A democratização do acesso à escola é concomitante com a emergência do insucesso escolar, erroneamente associado a perfis de alunos considerados "difíceis", como se à exclusão social correspondesse a exclusão escolar. Ao conhecerem e se envolverem com a história de vida e a realidade dos alunos, os docentes passaram a enxergá-los para além dos números e a ver o mundo através de uma outra ótica. Esses educadores se encontraram enquanto professores de escola pública, ao perceberem que passaram a contribuir para o desenvolvimento de uma educação de qualidade e, de alguma forma, na transformação de alunos com baixa estima, desacreditados na sua capacidade de aprender, em cidadãos conscientes e atuantes na sociedade.

Esses educadores descontruíram essa "leitura negativa" que olha o jovem e adulto em distorção idade-série em termos de faltas, de carências, sem levantar a questão da ineficácia pedagógica dos professores. Eles experienciaram uma "leitura positiva", uma outra postura epistemológica e metodológica proposta por um paradigma emergente que está na origem das políticas públicas para a promoção da igualdade de oportunidades, como a Metodologia Telessala $^{\mathrm{TM}}$. Todavia, sofreram preconceito por parte de diretores de escola e de professores do ensino regular, sempre prontos a denunciar a baixa do nível de ensino e o fim do pensamento, do saber e da cultura, de uma revolução pedagógica que até hoje ainda não se operou.

No que condiz ao objetivo específico de refletir sobre as possibilidades de aplicação da Metodologia Telessala ${ }^{\mathrm{TM}}$ em outros contextos educacionais, esses educadores acreditam que sim, mas que essa nova possibilidade de escola não seja entendida como mais uma resposta mas, antes, como o surgimento de novas perguntas sobre como resolver o problema da 
reprovação e evasão escolar de jovens e adultos das escolas públicas brasileiras. Para isso, é imprescindível garantir a formação continuada de professores e o acompanhamento pedagógico para fundamentar teórica e metodologicamente e vivenciar essa inovação pedagógica na prática antes e concomitante à sua aplicação na realidade.

Apesar de hoje se exigir que os professores ampliem seu papel para o de educadores, ainda não houve mudança significativa na sua formação político-pedagógica. $\mathrm{O}$ Paradigma da Instrução continua a ser incorporado ideologicamente à formação acadêmica e se verifica que os alunos saem das licenciaturas sem modificarem as suas crenças anteriores sobre o ensino, transmissor e expositivo. É necessário encontrar uma formação para o magistério que não esteja dominada por conhecimentos produzidos teoricamente por profissionais que nunca colocaram os pés numa escola, e que menosprezam e ignoram que as competências dos professores são construídas na prática e emergentes dos contextos escolares.

Nessa realidade profundamente marcada pelas desigualdades sociais, as formações de professores deveriam estar aliadas a paradigmas sócio-críticos que não deixassem de lado essa formação política-pedagógica dos professores e fossem voltados para a atuação de profissionais que contribuíssem para o desenvolvimento de uma sociedade mais igualitária. A formação continuada de professores ganharia muito se se organizasse em torno de situações concretas de "fracasso escolar" e, em uma abordagem preventiva, mobilizasse conhecimentos teóricos e práticos de sala de aula para, a partir da troca entre esses educadores, ir preenchendo as lacunas deficitárias da formação inicial de professores.

\section{REFERENCIAS}

AMADO, J. Manual de investigação qualitativa em educação. Coimbra: Imprensa da Universidade de Coimbra, 2013.

BARDIN, L. Análise de Conteúdo. Lisboa: Edições 70, 1979.

BEHRENS, M. O paradigma emergente e a prática pedagógica. Petrópolis: Vozes, 2013.

COSME, A. Ser professor: a acção docente como uma acção de intelocução qualificada. Porto: Livpisic, 2009.

CREMA, R. Além das disciplinas: reflexões sobre transdisciplinaridade geral. In: WEIL, P.; D'AMBRÓSIO, U.; CREMA, R. Rumo à nova transdisciplinaridade: sistemas abertos de conhecimento. São Paulo: Summos, 1993.

DELORS, J. Educação: um tesouro a descobrir. São Paulo: Cortez Editora, 1999. 
FIRME, T. P.; TEIXEIRA, J. F.; ALENCASTRO, I. P. de. Avaliação e aprimoramento curricular. Brasília: MEC, 1980.

FREIRE, M. Educador, educa a dor. São Paulo: Paz e Terra, 2010.

FREIRE, P. A Importância do ato de ler. São Paulo: Cortez, 2009.

. Educação como prática da liberdade. São Paulo: Paz e Terra, 1967.

Pedagogia da Autonomia: saberes necessários à prática educativa. São Paulo: Paz e

Terra, 1996.

Pedagogia do Oprimido. São Paulo: Paz e Terra, 1987.

GUIMAR ÂES, V. Incluir para transformar: Metodologia Telessala em cinco movimentos. Rio de Janeiro: Fundação Roberto Marinho, 2013.

MORGADO, J. C. O estudo de caso na investigação em educação. Santo Tirso: De Facto Editores, 2012.

MORIN, E. A cabeça bem-feita: repensar a reforma, reformar o pensamento. Rio de Janeiro: Bertrand Brasil, 2015.

PERRENOUD, P. Porquê construir competências a partir da escola? Desenvolvimento da autonomia e luta contra as desigualdades. Porto: A. S. A. Edições S. A., 2001.

PIAGET, J. Para onde vai a educação? Lisboa: LIVROS HORIZONTE LDA, 1990.

STAKE, R. E. A arte da investigação com estudos de caso. Lisboa: Fundação Calouste Gulbenkian, 2012.

TRINDADE, R. Escola, poder e saber: a relação pedagógica em debate. Porto: Livpsic, 2009. 